\title{
Sebaran Spasial Titik Panas (Hotspot) Berdasarkan Penutupan Lahan di Kabupaten Pesisir Selatan
}

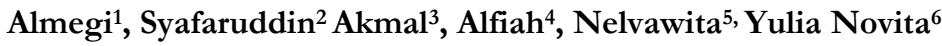 \\ 1,2,3,4,5 Program Studi Pendidikan Geografi, UIN Sultan Syarif Kasim Riau \\ e-mail: almegi@uin-suska.ac.id
}

\begin{abstract}
ABSTRAK. Kabupaten Pesisir Selatan merupakan salah satu daerah rawan kebakaran hutan dan lahan di Provinsi Sumatera Barat. Rata-rata areal yang terbakar tiap tahunnya dalam rentang tahun 2019-2021 adalah 1.002,7 ha. Tingginya angka kebakaran hutan dan lahan tersebut berbanding lurus dengan titik panas yang terpantau dalam jumlah besar tiap tahunnya. Tujuan tulisan ini adalah untuk melihat sebaran titik panas secara keruangan pada berbagai kelas penutup lahan di Kabupaten Pesisir Selatan sebagai indikasi awal wilayah rawan kebakaran hutan dan lahan. Data yang digunakan adalah data titik panas hasil interpretasi citra satelit NOAA20 tahun 2019-2021 yang bersumber dari dari laman resmi Kementerian Lingkugan Hidup dan Kehutanan https://sipongi.menlhk.go.id/ dan data penutup lahan hasil intrepretasi citra landsat 8 tahun 2020. Analisis spasial menggunakan aplikasi Sistem Informasi Geografi (SIG) berupa tumpang susun peta (superimpose) digunakan untuk melihat sebaran titik panas secara spasial berdasarkan kelas penutup lahan. Hasil analisis menunjukkan areal berpotensi tinggi terjadinya kebakaran hutan dan lahan adalah pada jenis penutup lahan berupa perkebunan dengan jumlah titik panas mencapai 82 titik kejadian $(24,48 \%)$ dan pertanian lahan kering sekunder dengan 69 titik panas $(20,60 \%)$. Secara keruangan wilayah di bagian selatan, yaitu Kec. Lunang Silaut, Kec. Basa IV Balai Tapan dan Kec. Pancung Soal merupakan wilayah rentan tinggi kebakaran hutan dan lahan karena areal perkebunan terkonsentrasi di wilayah ini dan titik panas pada areal pertanian lahan kering sebagian besar yaitu, 58 titik panas $(84,06 \%)$ berbatasan atau berdekatan dengan perkebunan.
\end{abstract}

Kata kunci: Kebakaran hutan dan ahan, Penutup Laban, Titik Panas

\section{PENDAHULUAN}

Kejadian kebakaran hutan dan lahan di Indonesia dalam skala besar terjadi pada tahun 1982-1983, 1991, 1994, 1997-1998, 2006 dan 2015 (Endrawati \& Yusnita, 2015). Dampak kebakaran hutan dan lahan tersebut tidak hanya berpengaruh terhadap kesehatan, ekonomi dan sosial masyarakat secara nasional, tetapi juga telah mempengaruhi negara tetangga. World Bank mencatat kebakaran hutan dan lahan pada tahun 2015 menimbulkan kerugian ekonomi yang diperoleh Indonesia mencapai lebih dari 200 triliun (Purnomo et al., 2017). Selain itu, kabut asap yang dihasilkan juga berdampak terhadap kesehatan masyarakat, terutama pada individu yang berisiko, diantaranya pasien dengan gangguan jantung dan pernafasan, kelompok usia lanjut, ibu hamil dan menyusui serta balita (Susanto et al., 2019).

Deteksi dini dalam upaya pencegahan dan pengendalian kebakaran hutan dan lahan pada saat ini disosialisasikan secara terbuka kepada publik melalui informasi sebaran titik panas (botspot) yang diperoleh dari data penginderaan jauh berupa data satelit. Titik panas merupakan istilah untuk sebuah piksel yang memiliki nilai temperatur di atas ambang batas (threshold) tertentu dari hasil interpretasi citra satelit, yang dapat digunakan sebagai indikasi kejadian kebakaran hutan dan lahan (KLHK, 2016). Satu titik panas mencerminkan suatu hamparan lahan yang mungkin terbakar sebagian atau seluruh bagiannya. Titik panas atau kelompok titik panas dalam jumlah besar dan berlangsung secara terus menerus merupakan indikator yang baik untuk mendeteksi terjadinya kebakaran hutan dan lahan.

Kabupaten Pesisir Selatan merupakan salah satu daerah rawan kebakaran hutan dan lahan di Provinsi Sumatera Barat. Rata-rata areal yang terbakar tiap tahunnya dalam tiga tahun terakhir adalah 1.002,7 Ha (Tabel 1). Angka ini tertinggi diantara kabupaten lainnya di Provinsi Sumatera 
Barat. Jumah titik panas dari liputan citra satelit, seperti NOAA20, TERRA/AQUA dan SNPP di wilayah ini juga besar tiap tahunnya.

Tabel 1. Luas Karhutla dan Jumlah Titik Panas Kabupaten Pesisir Selatan Tahun 2019-2021

\begin{tabular}{ccccc}
\hline \multirow{2}{*}{ Tahun } & \multirow{2}{*}{ Luas Karlutla $(\mathrm{Ha})$} & \multicolumn{3}{c}{ Titik Panas (Hotspot) } \\
\cline { 3 - 5 } & & NOAA20 & TERRA/AQUA & SNPP \\
\hline 2019 & 1.040 & 101 & 129 & 58 \\
2020 & 800 & 76 & 31 & 116 \\
2021 & 1.168 & 158 & 77 & 160 \\
\hline
\end{tabular}

Rata-tata

$1.002,7$

Sumber: https://sipongi.menlhk.go.id/

Kebakaran hutan dan lahan yang terjadi pada suatu wilayah dipengaruhi oleh banyak faktor, baik faktor fisik lingkungan maupun faktor sosial kemasyarakatan. Dalam banyak studi, kondisi tutupan lahan dijadikan sebagai faktor kunci yang mempengaruhi terjadinya kebakaran hutan dan lahan di suatu wilayah (BNPB, 2013); (Putra et al., 2018); (Antomi, 2019). Artikel ini mengambil fokus pada tutupan lahan, dimana variasi kelas tutupan lahan mempengaruhi kejadian kebakaran hutan dan lahan pada suatu wilayah yang dapat dideteksi dengan kemunculan titik panas. Tujuan penulisan artikel ini adalah untuk melihat dan memberikan gambaran secara keruangan sebaran titik panas pada berbagai kelas tutupan lahan sebagai indikasi awal daerah rawan kebakaran hutan dan lahan di Kabupaten Pesisir Selatan.

\section{METODE}

Artikel ini ditulis menggunakan pendekatan deskriptif dengan tujuan untuk mengambarkan secara faktual kemunculan titik panas pada berbagai kelas penutup lahan di wilayah studi. Cakupan wilayah studi adalah seluruh wilayah administrasi Kabupaten Pesisir Selatan dengan luas $6.049 \mathrm{~km}^{2}$. Seluruh data yang dianalis berbasis keruangan, sehingga dalam tahapan pengolahan dan analisis data memanfaatkaan aplikasi Sistem Informasi Geografi (SIG).

Data titik panas diperoleh dari laman resmi Kementerian Lingkugan Hidup dan Kehutanan https://sipongi.menlhk.go.id/ dengan data yang digunakan adalah titik panas hasil interpretasi citra NOAA20. Data tutupan lahan merupakan hasil intrepretasi citra satelit landsat 8 tahun 2020 menggunakan kaidah-kaidah penginderaan jauh dengan klasifikasi kelas penutup lahan mengacu kepada RSNI-1 Kelas Penutupan Lahan dalam Penafsiran Citra Optik Resolusi Sedang. Data spatial Batasan administrasi diperoleh dari instansi Bappeda Kab. Pesisir Selatan. Analisis spasial berupa tumpang susun peta (superimpose) antara data titik panas, data penutup lahan, dan data batas administasi dilakuan untuk mendapatkan peta sebaran titik panas berdasarkan jenis penutup lahan di Kabupaten Pesisir Selatan. Peta tersebut mengindikasikan kejadian kebakaran hutan dan lahan yang terjadi pada setiap kelas penutup lahan, sehingga akan teridentifikasi penutup lahan yang rentan terjadi kebakaran berdasarkan kepadatan titik panas.

\section{HASIL DAN PEMBAHASAN}

\section{Sebaran Titik Panas Kabupaten Pesisir Selatan}

Titik panas (botspot) di Kabupaten Pesisir Selatan pada tahun 2019-2021 tersebar secara tidak merata di seluruh wilayah kecamatan. Kumpulan titik panas dalam jumlah relatif banyak dan terjadi setiap tahunnya hanya terlihat pada wilayah bagian selatan, yaitu di Kec. Lunang Silaut dan kumpulan titik panah dalam jumlah relatif sedang di Kec. Basa IV Balai dan Kec. Pancung Soal, sementara untuk wilayah kecamatan lain jumlahnya kecil, tidak mengelompok dan tidak terjadi setiap tahunnya (Gambar 1).

Titik panas di Kec. Lunang Silaut tahun 2019 terdeteksi sebanyak 63 titik, tahun 2020 terdeteksi 48 titik dan tahun 2021 terdeteksi 87 titik. Titik panas di Kec. Basa IV Balai tahun 2019 terdeteksi sebanyak 21 titik, tahun 2020 terdeteksi 9 titik dan tahun 2021 terdeteksi 40 titik. Titik panas di Kec. Pancung Soal tahun 2019 terdekteksi sebanyak 12 titik, tahun 2020 terdeteksi 8 titik 
dan tahun 2021 terdeteksi 20 titik. Titik panas yang terdeteksi setiap tahunnya pada tiga wilayah kecamatan ini dengan pola cenderung mengelompok merupakan sebuah indikasi kuat bahwasanya daerah ini memiliki tingkat kerentanan tinggi terhadap kebakaran hutan dan lahan.

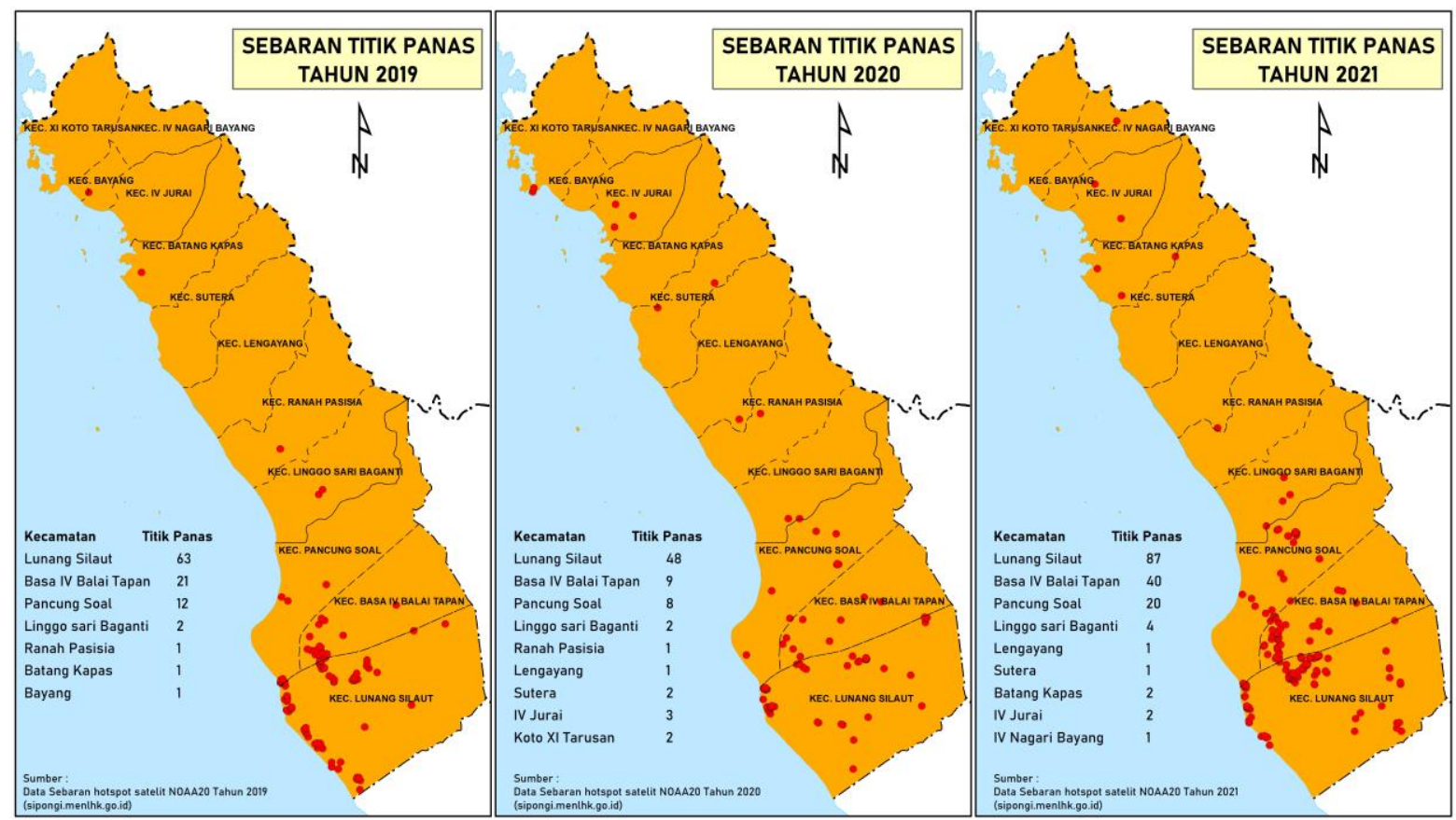

Gambar 1. Sebaran Titik Panas di Kab. Pesisir Selatan Tahun 2019-2021

\section{Sebaran Titik Panas Berdasarkan Penutup Lahan}

Hasil interpretasi pada citra satelit landsat 8 tahun 2020 diperoleh kelas penutup lahan Kab. Pesisir Selatan sebanyak 15 kelas (Tabel 2). Sebagaian besar penutup lahan berupa hutan lahan kering primer dengan luas 2.550,18 $\mathrm{km}^{2}(42,16 \%)$ yang berada di bagian timur memanjang dari utara ke selatan (Gambar 2), dan merupakan bagian dari Taman Nasional Kerinci Seblat (TNKS). Jenis penutup lahan lainnya yang mendominasi adalah pertanian lahan kering $(12,97 \%)$, pertanian lahan kering campur $(12,02 \%)$ dan perkebunan (10,78\%). Pertanian lahan kering dan pertanian lahan kering campur tersebar hampir merata diseluruh kecamatan, sedangkan perkebunan terkonsentrasi di wilayah selatan, yaitu di Kec. Lunang Silaut, Kec. Pancung Soal, Kec. Basa IV Balai dan Kec. Linggo Sari Baganti. Perkebunan dengan luas yang kecil juga terdapat di Kec. Ranah Pasisia dan Kec. Lenggayang.

Tabel 2. Kelas Penutup Lahan Kab. Pesisir selatan Tahun 2020

\begin{tabular}{clcc}
\hline No. & Kelas Pentutup Lahan & Luas $\mathbf{( K \mathbf { m } 2 )}$ & Persentase (\%) \\
\hline 1 & Hutan lahan kering primer & $2.550,18$ & 42,16 \\
2 & Hutan lahan kering sekunder & 397,83 & 6,58 \\
3 & Hutan rawa sekunder & 28,67 & 0,47 \\
4 & Hutan tanaman & 65,91 & 1,09 \\
5 & Perkebunan & 652,08 & 10,78 \\
6 & Pertanian lahan kering & 784,31 & 12,97 \\
7 & Pertanian lahan kering campur & 727,22 & 12,02 \\
8 & Belukar & 331,37 & 5,48 \\
9 & Belukar rawa & 82,87 & 1,37 \\
10 & Sawah & 335,50 & 5,55 \\
11 & Tambak & 0,25 & 0,004 \\
12 & Tanah terbuka & 30,21 & 0,50 \\
13 & Transmigrasi & 6,51 & 0,11 \\
14 & Permukiman & 29,86 & 0,49 \\
15 & Tubuh air & 26,24 & 0,43 \\
\hline & & $\mathbf{6 . 0 4 9 , 0 0}$ & $\mathbf{1 0 0 , 0 0}$ \\
\hline
\end{tabular}

Sumber: interpretasi citra salelit Landsat 8 
Peristiwa kebakaran hutan dan lahan yang terjadi berulang setiap tahunnya di Kab. Pesisir Selatan sangat dipengaruhi oleh jenis penutup lahan yang di di atasnya. Jenis penutup lahan yang berbeda memberikan tingkat kepekaan yang berbeda pula terhadap mudah atau sulitnya suatu lahan terbakar. Hasil analisis spasial (Tabel 3) menunjukkan bahwa titik panas dalam rentang tahun 2019-2021 berdasarkan penutup lahan, sebagian besar terdeteksi pada penutup lahan berupa perkebunan dengan 82 titik panas $(24,48 \%)$, kemudian pertanian lahan kering dengan 69 titik panas $(20,69 \%)$, belukar rawa 46 titik panas (13,73\%), belukar dengan 37 titik panas $(11,04 \%)$, hutan tanaman dengan 34 titik panas (10,15\%), pertanian lahan kering campuran dengan 26 titik panas $(7,76 \%)$, hutan rawa sekunder dengan 18 titik panas (5,37\%), hutan lahan kering sekunder dengan 11 titik panas (3,28\%), tanah terbuka dengan 9 titik panas $(2,69 \%)$, dan hutan lahan kering primer dengan 3 titik panas $(0,90 \%)$.

Tabel 3. Rasio Sebaran Titik Panas Berdasarkan Penutup Lahan

\begin{tabular}{|c|c|c|c|c|c|c|c|c|c|}
\hline \multirow{3}{*}{$\begin{array}{l}\mathbf{N} \\
\mathbf{o}\end{array}$} & \multirow{3}{*}{ Tutupan Lahan } & \multicolumn{6}{|c|}{ Titik Panas } & \multirow{3}{*}{ Total } & \multirow{3}{*}{ Rasio } \\
\hline & & \multicolumn{2}{|c|}{2019} & \multicolumn{2}{|c|}{2020} & \multicolumn{2}{|c|}{2021} & & \\
\hline & & $\mathrm{Jml}$ & $\%$ & Jml & $\%$ & Jml & $\%$ & & \\
\hline 1 & Hutan lahan kering primer & 1 & 0,99 & 2 & 2,63 & - & - & 3 & 0,90 \\
\hline 2 & Hutan lahan kering sekunder & 1 & 0,99 & 2 & 2,63 & 8 & 5,06 & 11 & 3,28 \\
\hline 3 & Hutan rawa sekunder & 4 & 3,96 & 5 & 6,58 & 9 & 5,70 & 18 & 5,37 \\
\hline 4 & Hutan tanaman & 5 & 4,95 & - & - & 29 & 18,35 & 34 & 10,15 \\
\hline 5 & Perkebunan & 26 & 25,74 & 32 & 42,11 & 24 & 15,19 & 82 & 24,48 \\
\hline 6 & Pertanian lahan kering & 20 & 19,80 & 12 & 15,79 & 37 & 23,42 & 69 & 20,60 \\
\hline 7 & Pertanian lahan kering campuran & 10 & 9,90 & 8 & 10,53 & 8 & 5,06 & 26 & 7,76 \\
\hline 8 & Belukar & 11 & 10,89 & 10 & 13,16 & 16 & 10,13 & 37 & 11,04 \\
\hline 9 & Belukar rawa & 18 & 17,82 & 3 & 3,95 & 25 & 15,82 & 46 & 13,73 \\
\hline \multirow[t]{2}{*}{10} & Tanah terbuka & 5 & 4,95 & 2 & 2,63 & 2 & 1,27 & 9 & 2,69 \\
\hline & Total & 101 & 100,00 & 76 & 100,00 & 158 & 100 & 335 & 100,00 \\
\hline
\end{tabular}

Sumber: pengolahan data tahun 2021

Jenis penutup lahan berupa perkebunan dan pertanian lahan kering memiliki rasio titik panas tertinggi $(>20 \%)$ diantara jenis penggunaan lahan lainnya yanng mengindikasikan areal dari kedua jenis penutup lahan tersebut berpotensi tinggi terjadinya kebakaran hutan dan lahan. Jenis penutup lahan berupa perkebunan setiap tahunnya (2019-2021) terdapat titik panas dengan jumlah yang besar, ini mengindikasikan areal perkebunan rentan terjadinya kebakaran hutan dan lahan. Tutupan lahan perkebunan sangat rentan akan kejadian kebakaran hutan dan lahan dimana kebakaran lahan yang terjadi pada praktik perkebunan menunjukkan bahwa penyiapan lahan perkebunan merupakan salah satu penyebab terjadinya kebakaran hutan dan lahan (Derik, 2019). Dilihat dari sebarannya (Gambar 2), penutup lahan perkebunan di Kab. Pesisir Selatan terkonsentrasi di wilayah Kec. Lunang Silaut dengan total areal perkebunan 400, $49 \mathrm{~km}^{2}$ (36,74\%). Luas lahan perkebunan ini berbanding lurus dengan jumlah titik panas yang tertinggi tiap tahunnya di Kec. Lunang Silaut (Gambar 1). Selain di Kec. Lunang silaut, perkebunan dengan areal relatif luas juga terdapat di Kec. Basa IV Balai Tapan dan Kec. Pancung Soal. Kedua kecamatan ini juga memiliki titik panas dalam jumlah cukup besar tiap tahunnya.

Pertanian lahan kering adalah jenis penutup lahan dengan sebaran titik panas terbanyak kedua dalam rentang tahun 2019-2021. Jika dilihat dari sebarannya pada peta (Gambar 2), titik panas pada areal pertanian lahan kering sebagian besar, yaitu 58 titik panas $(84,06 \%)$ juga terkonsentrasi di wilayah selatan, yaitu di wilayah Kec. Lunang Silaut, Kec. Basa IV Balai Tapan dan Kec. Pancung Soal, terutama pada areal pertanian lahan kering yang berdekatan dan atau bersebelahan dengan lahan perkebunan.

Jenis penutup lahan ketiga dengan sebaran titik panas terbanyak adalah belukar rawa yang secara keruangan (Gambar 3), belukar rawa hanya terdapat di wilayah selatan, yaitu di wilayah Kec. Lunang Silaut, Basa IV Balai Tapan dan Pancung Soal. Hal ini memperkuat hasil analisis bahwasanya wilayah Kec. Lunang Silaut, Kec. Basa IV Balai Tapan dan Kec. Pancung Soal merupakan wilayah rentan tinggi kebakaran hutan dan lahan di Kabupaten Pesisir Selatan. Belukar 
rawa tersebar di wilayah pimggiran perkebunan yang merupakan areal rawa yang sudah tidak memiliki hutan atau tidak ada tegakan vegetasi pohon. Kenampakan belukar rawa di lapangan akan sangat spesifik pada saat basah, yaitu adanya genangan air yang terkadang meliputi wilayah cukup luas dan dalam, sedangkan pada saat kering dan akan mudah terbakar.

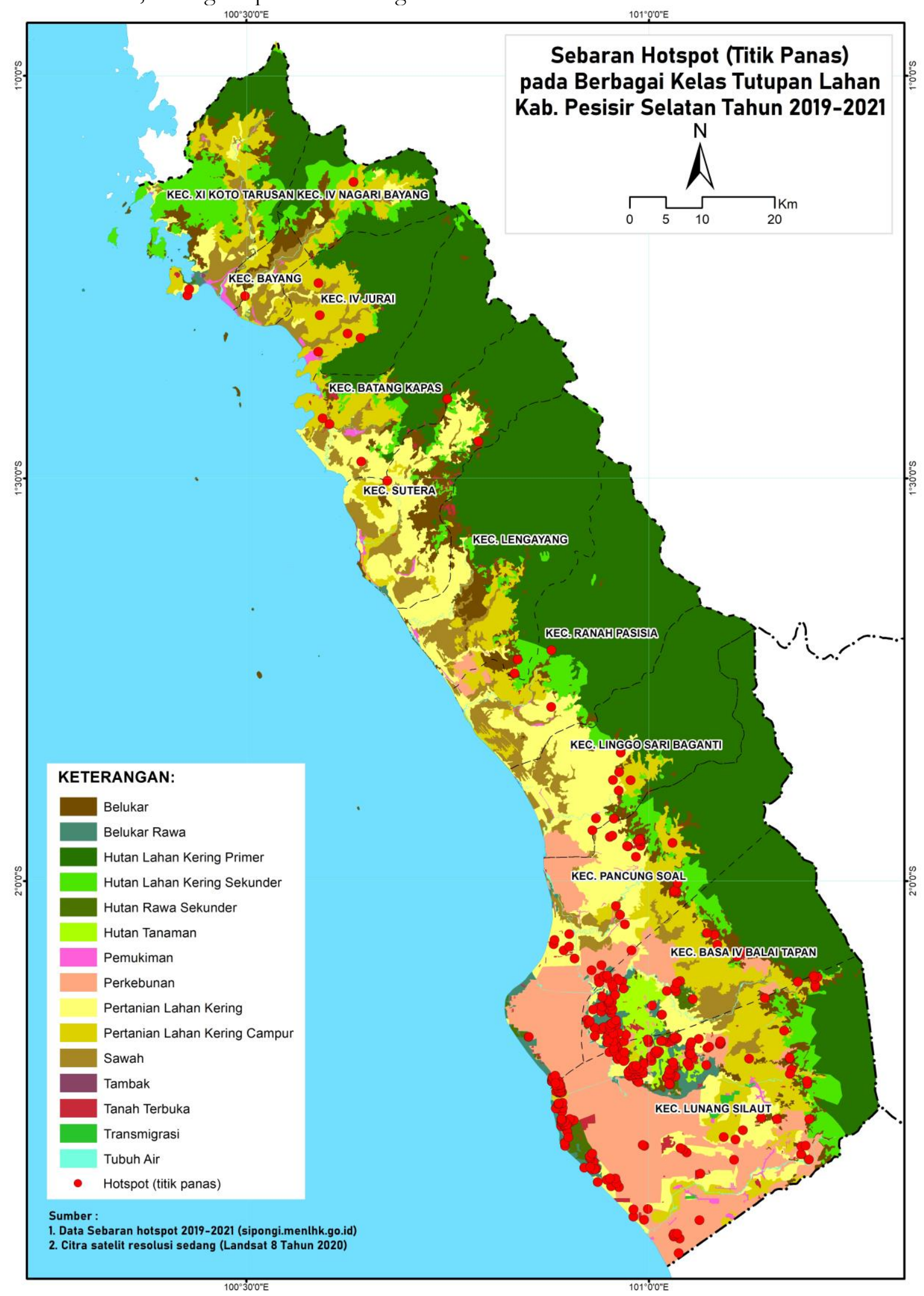

Gambar 2. Sebaran Titik Panas pada Berbagai Kelas Penutup Lahan 


\section{KESIMPULAN}

Sebaran titik panas di Kab. Pesisir Selatan pada tahun 2019-2021 tersebar secara tidak merata pada seluruh wilayah kecamatan. Kumpulan titik panas dalam jumlah yang relatif banyak terkonsentrasi pada wilayah bagian selatan, yaitu di Kec. Lunang Silaut, Kec. Basa IV Balai dan Kec. Pancung Soal. Jenis penggunaan lahan berpotensi tinggi terjadinya kebakaran hutan dan lahan adalah perkebunan dengan jumlah titik panas mencapai 82 titik kejadian $(24,48 \%)$ dan pertanian lahan kering dengan 69 titik panas (20,60\%). Pembukaan lahan untuk perkebunan dan pertanian pada lahan kering seringkali dilakuan secara tidak ramah lingkungan, sehingga lahan menjadi rentan terbakar pada saat kering.

Secara keruangan wilayah di bagian selatan, yaitu Kec. Lunang Silaut, Kec. Basa IV Balai Tapan dan Kec. Pancung Soal merupakan wilayah rentan tinggi kebakaran hutan dan lahan karena areal perkebunan terkonsetrasi di wilayah ini dan titik panas pada areal pertanian lahan kering sebagian besar yaitu, 58 titik panas $(84,06 \%)$ berbatasan atau berdekatan dengan perkebunan.

\section{REFERENSI}

Antomi, Y. (2019). Sebaran Daerah Rawan Kebakaran Hutan dan Lahan Berdasarkan Penutup Lahan Kabupaten Dharmasraya. Jurnal Spasial, 6(1), 19-26. https://doi.org/10.22202/js.v6i1.3318

BNPB. (2013). Indeks Rawan Bencana Indonesia. Badan Nasional Penanggulangan Bencana.

Derik, E. (2019). Perubahan Perladangan menjadi Perkebunan dan Dampaknya terhadap Kebakaran Hutan dan Lahan di Provinsi Riau. Jurnal Pengelolaan Sumberdaya Alam Dan Lingkungan (Journal of Natural Resources and Environmental Management), 9(2), 314-325. https://doi.org/10.29244/jpsl.9.2.314-325

Endrawati, \& Yusnita, R. (2015). Analisis Data Titik Panas (botspot) dan Kebakaran Hutan dan Laban 2015.

KLHK. (2016). Peraturan Menteri Lingkungan Hidup dan Kebutanan No P.32/MenLHK/Setjen/Kum.1/3/2016.

Purnomo, H., Shantiko, B., Sitorus, S., Gunawan, H., Achdiawan, R., Kartodihardjo, H., \& Dewayani, A. (2017). Fire economy and actor network of forest and land fires in Indonesia. Forest Policy and Economics, 78.

Putra, A., Ningsihh, T. R., \& Ikhwan, M. (2018). Pemetaan Darah Rawan Kebakaran Hutan dan Laban dengan Menggunaan Sistem Informasi Geografis (Studi KAsus Kecamatan Bukit Batu, Kabupaten Bengkalis). 9, 206-217.

Susanto, A., Arifin, N., Erlang, S., Zaini, J., Yunus, F., Fitriani, F., Isbaniah, F., Ikhsan, M., Ginanjar, A., \& Prasenohadi. (2019). Pencegahan dan Penanganan Dampak Akibat Asap Kebakaran Hutan. UI Press. 